\title{
Dysfunctional Attitudes and Anxiety Sensitivity in the Manifestation and First Onset of Social Anxiety Disorder versus Specific Phobia and Healthy: A Prospective Longitudinal Study
}

\author{
Myriam Rudaz', Eni S. Becker², Jürgen Margraf', Thomas Ledermann', Andrea H. Meyer4, \\ Michelle G. Craske ${ }^{5}$
}

${ }^{1}$ Department of Psychology, Utah State University, Logan, UT, USA

${ }^{2}$ Behavioural Science Institute, Radboud University of Nijmegen, Nijmegen, The Netherlands

${ }^{3}$ Department of Psychology, Ruhr-Universität Bochum, Bochum, Germany

${ }^{4}$ Department of Psychology, University of Basel, Basel, Switzerland

${ }^{5}$ Department of Psychology, University of California, Los Angeles, Los Angeles, CA, USA

Email: myriam.rudaz@usu.edu

How to cite this paper: Rudaz, M., Becker, E. S., Margraf, J., Ledermann, T., Meyer, A. H., \& Craske, M. G. (2016). Dysfunctional Attitudes and Anxiety Sensitivity in the Manifestation and First Onset of Social Anxiety Disorder versus Specific Phobia and Healthy: A Prospective Longitudinal Study. Psychology, 7, 1810-1823.

http://dx.doi.org/10.4236/psych.2016.714168

Received: October 28, 2016

Accepted: December 2, 2016

Published: December 5, 2016

Copyright $\odot 2016$ by authors and Scientific Research Publishing Inc. This work is licensed under the Creative Commons Attribution International License (CC BY 4.0).

http://creativecommons.org/licenses/by/4.0/

(c) (i) Open Access

\section{Abstract}

This study evaluated the role of two cognitive vulnerability factors, anxiety sensitivity and dysfunctional attitudes, in the prediction of the manifestation and onset of social anxiety disorder relative to specific phobia and relative to healthy controls. Women, aged between 18 and 24 years, were studied at baseline and 18 months later using the Anxiety Disorders Interview Schedule-Lifetime-ADIS-IV-L and the Anxiety Sensitivity Index-ASI and the Dysfunctional Attitude Scale-DAS. First, 52 women with current social anxiety disorder were compared to 97 women with current specific phobia and 1124 healthy controls (cross-sectional analysis). Second, 24 women with a first incidence of social anxiety disorder were compared to 55 women with a first incidence of specific phobia and 684 healthy controls (longitudinal analysis). Multiple logistic regression analyses, adjusted for baseline anxiety and depressive severity, revealed that a) dysfunctional attitudes were elevated in women with current social anxiety disorder versus healthy controls as well as women with current specific phobia in the cross-sectional analysis and b) dysfunctional attitudes were elevated in women who subsequently developed social anxiety disorder versus healthy controls in the longitudinal analysis. However, dysfunctional attitudes were not predictive for women who developed social anxiety disorder during the study relative to women who developed specific phobia. The results suggest that dysfunctional attitudes are a marker of severity for social anxiety disorder relative to other phobias and a risk factor for phobias more generally. Anxiety sensitivity seems not to contribute to the manifesta- 
tion and onset of social anxiety disorders.

\section{Keywords}

Dysfunctional Attitudes, Anxiety Sensitivity, Cognitive Styles, Social Anxiety

Disorder, Specific Phobia

\section{Introduction}

Social anxiety disorder is among the most prevalent of all psychological disorders, with $10.7 \%$ of persons in the US meeting diagnostic criteria for social anxiety disorder at some point in their lives (Kessler, Petukhova, Sampson, Zaslavsky, \& Wittchen, 2012). In Europe, this estimate is in the range of 1.9 to 13.7 percent for social anxiety disorder (Jacobi et al., 2014; Michael, Zetsche, \& Margraf, 2007). Women are affected more often than men, and the disorder occurs frequently in adolescence or early adulthood (Craske, 2003; Michael et al., 2007; Pigott, 2003). Despite advances in treatment research, there is a need for longitudinal research on the etiology of social anxiety disorder (e.g., Spence \& Rapee, 2016). The goal of this study was to evaluate the specificity of cognitive risk factors for social anxiety disorder versus specific phobia and versus healthy in a prospective, longitudinal design.

One potential risk factor for social anxiety disorder is beliefs about how one appears to others, as proposed in the model of social anxiety disorder by Rapee \& Heimberg (1997), an extension of earlier models by Carver \& Scheier (1988), Clark \& Wells (1995), and Schlenker \& Leary (1982). This model states that on encountering a social situation, socially anxious individuals form a mental representation of their external appearance and behavior as presumably seen by "the audience". Simultaneously they focus their attentional resources onto external indicators of negative evaluation (e.g., frowns, signs of boredom). Further, socially anxious individuals are hypothesized to formulate perfectionistic predictions of the performance standard or norm, which they expect the audience to utilize and determine whether they are performing in a manner that meets the specific standard. The discrepancy between the person's perception of the audience's appraisal of his performance (and, by extension, of himself) and the persons's perception of the audience's standard, is posited to lead to anxiety. Since anxiety consists of physiological, cognitive, and behavioral components, it subsequently influences the mental representation of appearance and behavior as seen by the audience, and the cycle is renewed.

We are not aware of any studies measuring the degree to which beliefs about how one appears to others prospectively contribute to the development of social anxiety disorder in longitudinal designs. Only cross-sectional research exists with constructs that are related to, but do not directly assess, beliefs about how one appears to others. Specifically, social anxiety disorder has been found to be cross-sectionally associated with elevated levels of anxiety sensitivity (ASI; Peterson \& Reiss, 1987; Reiss, Peterson, 
Gursky, \& McNally, 1986), or beliefs that anxiety and associated physical symptoms have harmful physical, social and mental consequences (Hazen, Walker, \& Stein, 1994/1995; McWilliams, Becker, Margraf, Clara, \& Vriends, 2007; Sapach, Carleton, Mulvogue, Weeks, \& Heimberg, 2015; Taylor, Koch, \& McNally, 1992).

Another potential risk factor for social anxiety disorder is depression. Data from epidemiological studies indicate that approximately $25 \%-31 \%$ of adolescents and young adults with social anxiety disorder have a comorbid depressive disorder (Essau, Conradt, \& Petermann, 1999; Wittchen, Stein, \& Kessler, 1999). Cross-sectional studies reveal that the personality trait of introversion is positively correlated with both depression (Clark \& Watson, 1991; Watson, Clark, \& Carey, 1988) and social anxiety disorder, but not other anxiety disorders (Watson, Gamez, \& Simms, 2005). Thus, depression and social anxiety disorder may share a personality diathesis.

Depression has been related to a cognitive diathesis as well, specifically dysfunctional attitudes (or, maladaptive underlying depressogenic "schemas"; Beck, 1967; Beck 1976; Beck, 1979), involving such themes as loss, failure, and worthlessness. This cognitive diathesis is often assessed with the Dysfunctional Attitude Scale (DAS; Weissman, 1979), which measures depressogenic attitudes about the self, the environment, and the future (cognitive triad; Beck, 1979). Several studies demonstrate that scores on the DAS prospectively predict subsequent depression (Alloy, Abramson, Whitehouse, Hogan, Panzarella, \& Rose, 2006; Zuroff, Igreja, \& Mongrain, 1990) although not always beyond the effects attributable to baseline depression (Otto, Teachman, Cohen, Soares, Vitonis, \& Harlow, 2007). Further, there is evidence of an association between high total scores on the DAS (Beck, Brown, Steer, \& Weissman, 1991) and the onset of depression (along with other disorders) in primary care settings (Weich, Churchill, \& Lewis, 2003). Given the overlap between depression and social anxiety disorder in terms of comorbidity and the personality trait of introversion, it is conceivable that they overlap in terms of cognitive vulnerability as well, especially cognitions pertaining to beliefs about the self.

The current study aimed to evaluate the role of anxiety sensitivity and dysfunctional attitudes in not just the manifestation but also the first onset of social anxiety disorder. Specifically, this article extends the findings of Vriends, Becker, Meyer, \& Margraf (2011), showing that the DAS predicted the first onset of social anxiety disorder (including women with comorbid disorders) relative to a non-incidence of social anxiety disorder group, whereas the ASI did not. The present study examines specificity of the cognitive variables, DAS and ASI, in predicting pure social anxiety disorder relative to another phobia group, namely specific phobia, and relative to healthy controls. Furthermore, the contribution of these cognitive variables was evaluated above and beyond the influence of baseline anxiety and depressive severity. To this end, cross-sectional as well as longitudinal comparisons were made. The cross-sectional groups were women with social anxiety disorder at baseline, women with specific phobia at baseline, and healthy control women. The longitudinal groups were women with a first incidence of social anxiety disorder, women with a first incidence of specific phobia, and healthy 
control women, over an 18 month interval.

Two main hypotheses were tested. First, we hypothesized that anxiety sensitivity and dysfunctional attitudes at baseline would add significant unique variance to the classification of baseline social anxiety disorder relative to healthy controls and relative to baseline specific phobia, beyond the variance attributable to baseline anxiety and depressive severity. Second, we hypothesized that anxiety sensitivity and dysfunctional attitudes at baseline would add unique variance to the classification of women with a first incidence of social anxiety disorder relative to healthy controls and relative to women with a first incidence of specific phobia by the 18 month follow-up, beyond the variance attributable to baseline anxiety and depressive severity.

\section{Method}

\subsection{Participants}

Participants were 1396 German women aged 18 to 24 years who participated at baseline and follow-up in the Dresden Predictor Study (DPS) of anxiety and depression, which is described in detail in Becker, Türke, Neumer, Soeder, Krause, \& Margraf (2000) and Trumpf, Vriends, Meyer, Becker, Neumer, \& Margraf (2010). This study used data of women who completed a diagnostic interview and self-report questionnaires at the two survey points, which were an average 18 months apart. Comparing the women who participated only at baseline $(n=1877)$ with the women who participated both at baseline and 18 months later, no significant differences emerged in overall psychological disorders measured with the Anxiety Disorders Interview Schedule-Lifetime at baseline, $t(802)=-1.40, p=0.161$ (two-tailed).

\subsection{Procedure and Measures}

The women received a letter with detailed information about the DPS and a reply card to confirm participation. The interested women were invited for the diagnostic interview conducted by trained interviewers either psychology students, psychologists or physicians. In addition, a package of questionnaires was administered. Participants willing to join the second diagnostic interview were invited on average 18 months later. There were no financial reimbursements for participants in the study.

Diagnostic assessment. The diagnostic assessments at baseline and follow-up were based on the Anxiety Disorders Interview Schedule-Lifetime (ADIS-IV-L; Brown, Barlow, \& Di Nardo, 1994), German version (Diagnostisches Interview für Psychische Störungen-Forschungsversion/F-DIPS; Margraf, Schneider, Soeder, Neumer, \& Becker, 1996). The German version of the ADIS-IV-L is a structured interview for diagnosing Axis I disorders, including anxiety disorders, affective disorders, somatoform disorders, substance-use disorders, eating disorders, and children's disorders, according to DSMIV (American Psychiatric Association, 1994). In the baseline interview, questions were asked about psychological problems during the entire lifetime and during the last seven days (lifetime and point prevalence, respectively). The follow-up interviews referred to the psychological problems that had occurred since the baseline interview and during 
the last seven days (period and point prevalence, respectively). The inter-rater reliabilities of the German version of the ADIS-IV-L (Yule's Y coefficient) in patient samples were 0.98 for social anxiety disorder and 0.98 for specific phobia, respectively ( $n=237$; Suppiger, In-Albon, Herren, Bader, Schneider, \& Margraf, 2008). Retest-reliabilities across the groups of disorders were 0.68 - 0.79 (Kappa coefficient) and 0.67 - 1.0 (Yule's coefficient; Schneider, Margraf, Spörkel, \& Franzen, 1992). In addition, the interview has demonstrated high validity (In-Albon, Suppiger, Schlup, Wendler, Margraf, \& Schneider, 2008; Margraf, Schneider, \& Spörkel, 1991), as well as good acceptance in clinical practice and research settings (Suppiger, In-Albon, Hendriksen, Hermann, Margraf, \& Schneider, 2009).

Clinical severity rating. Based on the ADIS-IV-L (Brown et al., 1994), the clinicians rated the severity of distress and interference for each disorder, on a scale ranging from 0 (not severe at all) to 8 (very severe). A diagnosis was considered clinically severe when the clinical severity rating was of a 4 or above.

Number of feared social and specific situations. In the ADIS-IV-L (Brown et al., 1994), the interviewer read a list of 13 social situations (e.g., public speaking, talking to people in authority) and 17 specific situations (e.g., animals, heights) and asked the women to indicate if they "became anxious" or "wanted to avoid" each situation. If the answer was "yes", the interviewer inquired about strength of anxiety and degree of avoidance, which were rated on a scale of 0 (no anxiety/no avoidance) to 8 (very strong anxiety/very severe avoidance).

Interviewers, training procedure, and supervision. Interviewers had a psychological or medical background. They underwent an intensive 40-hour training on psychological disorders, their rating and the conduct of the interviews and subsequently attended supervision meetings every two weeks. The written protocol for each interview was proof read by supervisors (e.g., were all answers complete, and did the answers match the diagnosis assigned). Unclear cases were discussed, and if necessary a consensus diagnosis was given.

Anxiety Sensitivity Index. The Anxiety Sensitivity Index (ASI; Peterson \& Reiss, 1987; Reiss et al., 1986; German version: Ehlers \& Margraf, 1993) is a 16-item self-report questionnaire to measure the tendency to fear the somatic and cognitive symptoms of anxiety. Participants rate the extent to which they agree or disagree with each item (e.g., "It is important for me not to appear nervous") on a 5-point Likert scale ranging form "very little" to "very much". Higher scores on the ASI are indicative of greater levels of anxiety sensitivity. In the current sample, the ASI had good internal consistency for the total score $(\alpha=0.82)$.

Dysfunctional Attitude Scale. The Dysfunctional Attitude Scale (DAS Weissman, 1979; German version: Hautzinger, Luka, \& Trautmann, 1985) is a 40-item self-report questionnaire to assess depression-typical negative and inappropriate attitudes that construe how a person perceives one's self, the environment and the future (e.g., "What other people think of me is very important"). Responses range on a 7-point scale from "total agreement" to "total disagreement" with higher scores indicating greater dys- 
functional attitudes. In the current sample, the DAS had good internal consistency for the total score (Cronbach's $\alpha=0.88$ ).

Beck Anxiety Inventory. The Beck Anxiety Inventory (BAI; Beck \& Steer, 1987; German version: Margraf \& Ehlers, 2007) is a 21-item self-report inventory of the severity of anxiety symptoms (e.g., feeling hot, or fear of losing control). Participants are asked to rate how much each symptom bothered them "during the past week, including today" on a 4-point-Likert scale ranging from "not at all" to "severely-I could barely stand it". In the current sample, the BAI had good internal consistency $(\alpha=0.82)$. The BAI was used as a measure of baseline anxiety severity.

Beck Depression Inventory. The Beck Depression Inventory (BDI; Beck \& Steer, 1987; German version: Hautzinger, 1991; Hautzinger, Bailer, Worall, \& Keller, 1995) is a 21-item self-report inventory of the severity of depressive symptoms. The questionnaire involves somatic symptoms (sleep, appetite) as well as items inquiring about mood (sadness, guilt) and cognitions (hopelessness, suicidal ideation). Each item consists of four self-evaluative statements of increasing severity. In the current sample, the BDI had good internal consistency ( $\alpha=0.82$ ). The BDI was used as a measure of baseline depressive severity.

\subsection{Definition of the Groups}

On the basis of the diagnostic interview, groups for cross-sectional and longitudinal comparisons were composed. The cross-sectional comparison groups were 52 women with a baseline social anxiety disorder (B-SAD; based on 7-day point prevalence at baseline), 97 women with a baseline specific phobia (B-SP; based on 7-day point prevalence at baseline) and 1124 baseline healthy women (B-H; based on 7-day point prevalence at baseline). The longitudinal comparison groups were 24 women with a first incidence of social anxiety disorder (I-SAD; no lifetime diagnosis at baseline and period prevalence at follow-up), 55 women with a first incidence of specific phobia (I-SP; no lifetime diagnosis at baseline and period prevalence at follow-up), and 684 follow-up healthy women (F-H; no lifetime diagnosis at baseline and no period prevalence at follow-up).

Both the baseline and the incidence phobia groups consisted of women with social anxiety disorder or specific phobia diagnoses in the absence of other psychological diagnoses. Thus, women with comorbid specific and social anxiety disorder diagnoses and women with other psychological diagnoses were not entered in the analyses (123 for the cross-sectional and 633 for the longitudinal analyses, respectively).

Mean age at baseline was 21 years $(S D=1.62$ to 2.00$)$ for all groups. There were no significant differences between the baseline groups in relationship status, education, or engagement in paid employment. Also, there were no significant differences between the incidence groups in education. However, there were significant differences between the incidence groups in relationship status ( $64.8 \%$ of the F-H, $37.5 \%$ of the I-SAD, and $72.7 \%$ of the I-SP group were in a romantic relationship, $\chi^{2}(2)=9.29, p=0.010$ ) and engagement in paid employment (46.9\% of the F-H, $20.8 \%$ of the I-SAD, and $40.0 \%$ of 
the I-SP group were engaged in paid employment, $\chi^{2}(2)=7.31, p=0.026$ ).

\subsection{Statistical Analyses}

Multinomial hierarchical logistic regression analysis was conducted to compare the groups using the software SPSS. Two models were estimated, one comparing B-SAD with B-H and B-SP, and another one comparing I-SAD with F-H and I-SP. In both models, the variables BAI total and BDI total were entered on the first step as control variables, and the cognitive variables ASI total and DAS total were entered on the second step. In order to compare the odds ratios, the predictor variables were standardized using z-transformation.

\section{Results}

\subsection{Preliminary Analyses}

The clinical severity rating was at or above the "clinical cutoff" (i.e., score of 4 or higher) for all groups, except B-SAD where it was slightly below the cut off: B-SP $-M d n=$ 4.00, $M=4.25, S D=1.20$; I-SP $-M d n=4.00, M=4.61, S D=2.17$; B-SAD $-M d n=$ 4.00, $M=3.88, S D=1.07$; and I-SAD $-M d n=4.00, M=4.08, S D=1.10$. Women of the B-SAD or I-SAD group mostly feared public speaking: B-SAD $-M d n=4.00, M=$ $4.10, S D=1.96 ; \mathrm{I}-\mathrm{SAD}-M d n=4.00, M=3.58, S D=2.12$. Women of the B-SP or I-SP group mostly feared animals: B-SP $-M d n=4.00, M=3.87, S D=2.64$; I-SP $-M d n=$ 4.00, $M=3.40, S D=2.68$.

Table 1 presents the product-moment correlations among the study variables at baseline. As expected, all correlations were positive. Between the DAS and ASI the correlation was small in size, whereas between the BDI and BAI it was strong.

\subsection{Main Analyses}

The descriptive statistics and the results of the logistic regression analyses for the crosssectional and longitudinal comparisons are given in Table 2 and Table 3, respectively.

Cross-sectional. Overall, $6 \%$ of the variance was explained, with the BAI and BDI explaining $3 \%$ of the total variance. The comparison between B-SAD and $\mathrm{B}-\mathrm{H}$ women yielded significant effects for the BAI and DAS, with the DAS being the strongest predictor. The predicted probability of having a B-SAD diagnosis vs. being in the $\mathrm{B}-\mathrm{H}$ group increases as the BAI or DAS survey response increases. These results indicated

Table 1. Product-Moment correlations among variables at baseline.

\begin{tabular}{lccc}
\hline & 1 & 2 & 3 \\
\hline 1 BAI total & - & & \\
2 BDI total & 0.62 & - & - \\
3 ASI total & 0.40 & 0.35 & 0.28 \\
4 DAS total & 0.23 & 0.32 & \\
\hline
\end{tabular}

Note. $N=1396 . \mathrm{BAI}=$ Beck Anxiety Inventory, BDI $=$ Beck Depression Inventory, ASI $=$ Anxiety Sensitivity Index, DAS $=$ Dysfunctional Attitude Scale. 
Table 2. Multiple logistic regression analysis comparing the baseline social anxiety disorder group to the baseline healthy group and the baseline specific phobia group.

\begin{tabular}{|c|c|c|c|c|c|c|c|c|c|c|c|}
\hline \multirow{2}{*}{ Cross-sectional } & \multicolumn{2}{|c|}{$\begin{array}{l}\text { Baseline H } \\
(n=1124)\end{array}$} & \multicolumn{2}{|c|}{$\begin{array}{l}\text { Baseline SAD } \\
\quad(n=52)\end{array}$} & \multicolumn{2}{|c|}{$\begin{array}{l}\text { Baseline SP } \\
\quad(n=97)\end{array}$} & \multicolumn{2}{|c|}{$\begin{array}{c}\text { Baseline SAD } \\
\text { vs. Baseline } \mathrm{H}^{\mathrm{a}}\end{array}$} & \multicolumn{2}{|c|}{$\begin{array}{c}\text { Baseline SAD } \\
\text { vs. Baseline SP }\end{array}$} & \multirow[b]{2}{*}{$R^{2}$} \\
\hline & $M$ & $S D$ & $M$ & $S D$ & $M$ & $S D$ & OR & $95 \% \mathrm{CI}$ & OR & $95 \%$ CI & \\
\hline Step 1 & & & & & & & & & & & 0.03 \\
\hline BAI total & 4.06 & 4.36 & 6.43 & 6.39 & 4.69 & 4.21 & $1.51^{*}$ & {$[1.04,2.19]$} & 1.57 & {$[0.98,2.52]$} & \\
\hline Step 2 & & & & & & & & & & & 0.06 \\
\hline ASI total & 13.41 & 7.83 & 15.25 & 6.99 & 14.71 & 8.32 & 1.09 & {$[0.80,1.48]$} & 0.89 & {$[0.61,1.28]$} & \\
\hline DAS total & 109.92 & 22.78 & 123.42 & 29.36 & 111.85 & 24.28 & $1.80^{* * *}$ & {$[1.33,2.43]$} & $1.75^{\star *}$ & {$[1.22,2.51]$} & \\
\hline
\end{tabular}

Note. $\mathrm{H}=$ healthy. $\mathrm{SAD}=$ social anxiety disorder. $\mathrm{SP}=$ specific phobia. All predictors were z-transformed. $\mathrm{BAI}=$ Beck Anxiety Inventory, BDI $=\mathrm{Beck}$ Depression Inventory, ASI = Anxiety Sensitivity Index, DAS = Dysfunctional Attitude Scale. Possible ranges: BAI total $0-63$, BDI total $0-22$, DAS total $0-240$, ASI total $0-64$. $\mathrm{OR}=$ odds ratio. $\mathrm{CI}=$ confidence interval. $R^{2}=$ Pseudo R-Square of Nagelkerke. ${ }^{a}$ reference group. ${ }^{*} p<0.05 .{ }^{* *} p<0.01 .{ }^{* *} p<0.001(2$-tailed).

Table 3. Multiple logistic regression analysis comparing the incidence social anxiety disorder group to the follow-up healthy group and the incidence specific phobia group.

\begin{tabular}{|c|c|c|c|c|c|c|c|c|c|c|c|}
\hline \multirow[t]{2}{*}{ Longitudinal } & \multicolumn{2}{|c|}{$\begin{array}{l}\text { Follow-up H } \\
\quad(n=684)\end{array}$} & \multicolumn{2}{|c|}{$\begin{array}{c}\text { Incidence SAD } \\
\quad(n=24)\end{array}$} & \multicolumn{2}{|c|}{$\begin{array}{c}\text { Incidence SP } \\
\quad(n=55)\end{array}$} & \multicolumn{2}{|c|}{$\begin{array}{l}\text { Incidence SAD } \\
\text { vs. Follow-up } \mathrm{H}^{\mathrm{a}}\end{array}$} & \multicolumn{2}{|c|}{$\begin{array}{l}\text { Incidence SAD } \\
\text { vs. Incidence } \mathrm{SP}^{\mathrm{a}}\end{array}$} & \multirow[b]{2}{*}{$R^{2}$} \\
\hline & $M$ & $S D$ & $M$ & $S D$ & $M$ & $S D$ & OR & $95 \%$-CI & OR & $95 \%$-CI & \\
\hline BAI total & 3.22 & 3.49 & 3.74 & 4.59 & 4.87 & 4.04 & 1.15 & {$[0.50,2.67]$} & 0.92 & {$[0.35,2.42]$} & \\
\hline BDI total & 3.77 & 3.59 & 4.32 & 2.82 & 5.58 & 4.91 & 1.06 & {$[0.52,2.16]$} & 0.70 & {$[0.31,1.57]$} & \\
\hline ASI total & 12.78 & 7.30 & 12.72 & 6.07 & 15.05 & 9.09 & 0.90 & {$[0.56,1.46]$} & 0.88 & {$[0.50,1.56]$} & \\
\hline DAS total & 107.19 & 22.25 & 115.47 & 20.91 & 113.05 & 23.27 & $1.65^{\star}$ & {$[1.03,2.65]$} & 1.45 & {$[0.83,2.55]$} & \\
\hline
\end{tabular}

Note. $\mathrm{H}=$ healthy. $\mathrm{SAD}=$ social anxiety disorder. $\mathrm{SP}=$ specific phobia. All predictors were z-transformed. BAI $=$ Beck Anxiety Inventory, BDI $=$ Beck Depression Inventory, ASI $=$ Anxiety Sensitivity Index, DAS $=$ Dysfunctional Attitude Scale. Possible ranges: BAI total $0-63$, BDI total $0-22$, DAS total $0-240$, ASI total $0-64$. $\mathrm{OR}=$ odds ratio. $\mathrm{CI}=$ confidence interval. $R^{2}=$ Pseudo R-Square of Nagelkerke. ${ }^{a}$ reference group. ${ }^{*} p<0.05 .{ }^{* *} p<0.01 .{ }^{* * *} p<0.001(2$-tailed).

that women with a high BAI or DAS score were more likely to have a social anxiety disorder than being healthy. The ASI and BDI did not contribute to the prediction of the B-SAD vs. B-H group significantly. The comparison between B-SAD and B-SP showed a significant effect for the DAS with an increase in the DAS score yields an increase in the predicted probability of being in the B-SAD vs. the B-SP group. This result showed that women with more dysfunctional attitudes are more likely being in the B-SAD group than in B-SP group. The ASI, BAI, and BDI did not contribute significantly to the prediction of the B-SAD vs. B-SP group.

Longitudinal. Overall, the model explained $4 \%$ of the variance, with the BAI and BDI explaining $1 \%$ of the total variance. The comparison between I-SAD and F-H women revealed a significant effect for the DAS with a higher predicted probability of being in the I-SAD vs. the F-H group for women high on the DAS. This result indicates that women who developed a social anxiety disorder between baseline and follow-up 
had more dysfunctional attitudes at baseline compared to women who remained healthy over the whole study time of 18 months. The ASI total did not contribute significantly to the model. The comparison between the two first incidence phobia groups yielded no significant effects. This result indicated that women who developed social anxiety disorder during the study did not differ significantly on dysfunctional attitudes or anxiety sensitivity from women who developed specific phobia during the study.

\subsection{Additional Analyses}

Due to significant differences in relationship status and engagement in paid employment between the incidence groups (see above), we additionally controlled for the variables romantic partner (i.e., relationship status) and paid employment (i.e., engagement in paid employment) in two separate logistic regression models. The variable romantic partner was a significant predictor for I-SAD relative to $\mathrm{F}-\mathrm{H}$ and relative to I-SP $(\mathrm{OR}=0.59,95 \% \mathrm{CI}[0.39,0.90], p<0.05)$. These findings suggest that being single increases the risk for a first onset of social anxiety disorder relative to healthy controls and to the first onset of specific phobia. The variable "paid employment" was not significant. The results for BAI, BDI, DAS, and ASI remained the same as in the original regression models.

In addition, analyses were conducted including women with comorbid diagnoses in the phobia groups (B-SAD: $n=73$, B-SP: $n=112$; I-SAD: $n=33$, I-SP: $n=62$ ), although excluding women with comorbid social anxiety disorder and specific phobia (18 for the cross-sectional and 11 for the longitudinal analyses). The control groups (B-H and F-H) included women with either no psychological disorders or psychological disorders other than social anxiety disorder or specific phobia (B-C: $n=1,193$; I-C: $n=$ 748). The results remained essentially the same as in the original regression models with the exception of the comparison $\mathrm{B}-\mathrm{SAD}$ versus $\mathrm{B}-\mathrm{C}$ : the $\mathrm{BAI}$ was not a significant predictor but the $\mathrm{BDI}$ was ( $\mathrm{OR}=1.36,95 \% \mathrm{CI}[1.04,1.78], p<0.05)$, indicating that the higher the BDI score the higher the probability of being in the B-SAD vs. the B-C group.

\section{Discussion}

The present study aimed to evaluate the degree to which cognitive variables related to social anxiety disorder at baseline and predicted first incidence of social anxiety disorder between baseline and follow-up, and whether these variables were specific to social anxiety disorder relative to specific phobia and relative to healthy controls. As hypothesized, dysfunctional attitudes at baseline were predictive for women with current social anxiety disorder relative to women with current specific phobia and relative to healthy control women.

These results provide further support for the overlap between social anxiety disorder and depression (Essau et al., 1999; Wittchen et al., 1999). Consistent with our hypothesis, women with current social anxiety disorder reported more dysfunctional attitudes than healthy controls. Also, dysfunctional attitudes differentiated social anxiety disord- 
er from specific phobia at baseline. This finding suggests a specific effect of dysfunctional attitudes on the manifestation of social anxiety disorder in particular rather than a general effect on the manifestation of phobias more broadly. Furthermore, dysfunctional attitudes added unique variance to the classification of women with an incidence of social anxiety disorder relative to healthy women, over and above initial anxiety and depressive levels, suggesting that they may play a crucial role in the first onset of social anxiety disorder. However, there was no evidence for specificity in the prediction of social anxiety disorder, since dysfunctional attitudes did not differentiate women who developed social anxiety disorder from women who developed specific phobia. Thus, dysfunctional attitudes appear to be a non-specific predictor of both social anxiety disorder and specific phobia. The DAS results can be interpreted in terms of the cognitive model of social anxiety disorder (Rapee \& Heimberg, 1997) because dysfunctional attitudes overlap with the construct of a mental representation of the self as seen by an audience. As would be predicted by the cyclical model of social anxiety disorder the dysfunctional attitudes contributed to the onset of social anxiety disorders and once social anxiety disorders manifested, dysfunctional attitudes became a more defining feature of social anxiety disorder compared to other phobias. However, the mechanisms by which dysfunctional attitudes contribute to specific phobias remain unclear but it may be that maladaptive underlying depressogenic "schemas" may enhance the vulnerability for the onset of phobias in general.

In contrast to our hypotheses, anxiety sensitivity was not more elevated in those with social anxiety disorder relative to controls at baseline. Also, anxiety sensitivity did not contribute to the prediction of the first onset of social anxiety disorder, even when including comorbidity. These later findings are at odds with prior research (Hazen et al., 1994/1995; McWilliams et al., 2007; Sapach et al., 2015; Taylor et al., 1992) and may be due to the largely nongeneralized nature of our social anxiety disorder population. Thus, with a more generalized social anxiety disorder group, anxiety sensitivity may have played a greater role in the manifestation and onset of social anxiety disorder.

Neither women's relationship status nor engagement in paid employment changed the pattern of results, but being single was a specific predictor for the first onset of social anxiety disorder indicating that women with no partner are at greater risk of developing a social anxiety disorder compared to other phobias. Using comorbid groups, depressive severity explained additional variance between the social anxiety disorder and the healthy controls in the cross-sectional comparison.

The present study has several strengths, including the longitudinal design, the standardized assessment of DSM-IV diagnoses of specific phobia and social anxiety disorder, and the large sample size. However, the generalization of the present results must be qualified by several limitations. First, our community sample consisted of young women aged between 18 and 24 years from Germany. Therefore, no conclusions can be drawn for males or for younger or older women, other cultures, or clinical samples. Second, the lifetime and period diagnoses were based on retrospective recall, which may be biased. Third, according to DSM-IV, social anxiety disorder can be conceptua- 
lized as consisting of a generalized subtype versus a non-generalized subtype. As already mentioned, current findings may be more relevant to the non-generalized social anxiety disorder subtype, given that women in this sample were most fearful of public speaking. Also, the results may be particular for specific phobias that consist mostly of animal phobias. Fourth, the groups with social anxiety disorder and specific phobia at baseline and follow-up, while of clinical severity in most cases, were not as severe as typically seen in clinical settings, thereby limiting generalizability to clinical samples.

\section{Conclusion}

In conclusion, our findings indicate that dysfunctional attitudes may play a crucial role in the manifestation and first onset of social anxiety disorder in young women compared to healthy controls, above and beyond the effects of symptoms of anxiety and depression. Further, this study highlighted that dysfunctional attitudes were specific to the manifestation of social anxiety disorder relative to specific phobia, although they were not specific in risk conferred to the development of social anxiety disorder relative to specific phobia. The pathway through which dysfunctional attitudes contribute to social anxiety disorder may be attributable to beliefs about how one appears to others, as explicated in the cognitive model of social anxiety disorder. However, the pathway through which dysfunctional attitudes contribute to specific phobias is not clear. Finally, it should be noted that the amount of variance explained, while significant, is not large and that other variables not measured warrant further research attention.

\section{Acknowledgements}

This study was supported by the German Ministry of Science, Research and Education grant DLR 01EG9410 and by the Swiss National Science Foundation grants 51A240104890, PBBS1-120509, and PBFR1-120897. We would like to thank the many people who helped with the study.

\section{References}

Alloy, L. B., Abramson, L. Y., Whitehouse, W. G., Hogan, M. E., Panzarella, C., \& Rose, D. T. (2006). Prospective Incidence of First Onsets and Recurrences of Depression in Individuals at High and Low Cognitive Risk for Depression. Journal of Abnormal Psychology, 115, 145-156. https:/doi.org/10.1037/0021-843X.115.1.145

American Psychiatric Association (1994). Diagnostic and Statistical Manual of Mental Disorders (DSM). Washington DC: American Psychiatric Association.

Beck, A. T. (1967). Depression. New York: Harper and Row.

Beck, A. T. (1976). Cognitive Therapy and the Emotional Disorders. Oxford: International Universities Press.

Beck, A. T. (1979). Cognitive Therapy of Depression. New York: Guilford Press.

Beck, A. T., \& Steer, R. (1987). Manual for the Revised Beck Depression Inventory. San Antonio, TX: Psychological Corporation.

Beck, A. T., Brown, G., Steer, R. A., \& Weissman, A. N. (1991). Factor Analysis of the Dysfunctional Attitude Scale in a Clinical Population. Psychological Assessment: A Journal of Con- 
sulting and Clinical Psychology, 3, 478-483. https:/doi.org/10.1037/1040-3590.3.3.478

Becker, E. S., Türke, V., Neumer, S., Soeder, U., Krause, P., \& Margraf, J. (2000). Incidence and Prevalence Rates of Mental Disorders in a Community Sample of Young Women: Results of the "Dresden Study". In G. Heeb-Erler, R. Manz, \& W. Kirch (Eds.), Public Health Research and Practice: Report of the Public Health Research Association Saxony (pp. 259-292). Regensburg: Roderer.

Brown, T. A., Barlow, D. H., \& Di Nardo, P. A. (1994). Anxiety Disorders Interview Schedule for DSM-IV (ADIS-IV): Client Interview Schedule. New York: Oxford University Press.

Carver, C. S., \& Scheier, M. F. (1988). A Control-Process Perspective on Anxiety. Anxiety Research, 1, 17-22. https:/doi.org/10.1080/10615808808248217

Clark, D. M., \& Wells, A. (1995). A Cognitive Model of Social Phobia. In R. G. Heimberg, M. R. Liebowitz, D. A. Hope, F. R. Schneier, R. G. Heimberg, M. R. Liebowitz, D. A. Hope, \& F. R. Schneier (Eds.), Social Phobia: Diagnosis, Assessment, and Treatment (pp. 69-93). New York: Guilford Press.

Clark, L. A., \& Watson, D. (1991). Tripartite Model of Anxiety and Depression: Psychometric Evidence and Taxonomic Implications. Journal of Abnormal Psychology, 100, 316-336. https:/doi.org/10.1037/0021-843X.100.3.316

Craske, M. G. (2003). Origins of Phobias and Anxiety Disorders: Why More Women than Men? Amsterdam: Elsevier.

Ehlers, A., \& Margraf, J. (1993). “Angst vor der Angst”: Ein neues Konzept in der Diagnostik der Angststörungen ["Fear of Fear": A New Concept in the Assessment of Anxiety Disorders]. Verhaltenstherapie, 3, 14-24. https:/doi.org/10.1159/000258732

Essau, C. A., Conradt, J., \& Petermann, F. (1999). Frequency and Comorbidity of Social Phobia and Social Fears in Adolescents. Behaviour Research and Therapy, 37, 831-843. https:/doi.org/10.1016/S0005-7967(98)00179-X

Hautzinger, M. (1991). Das Beck-Depressioninventar (BDI) in der Klinik [The German Version of the Beck Depression Inventory (BDI) in Clinical Use]. Der Nervenarzt, 62, 689-696.

Hautzinger, M., Bailer, M., Worall, H., \& Keller, F. (1995). Beck-Depressions-Inventar (BDI) [Beck-Depression-Inventory (BDI)]. Bern: Huber.

Hautzinger, M., Luka, U., \& Trautmann, R. D. (1985). Skala dysfunktionaler Einstellungen-Eine deutsche Version der Dysfunctional Attitude Scale [Dysfunctional Attitude Scale: A German Version of the Dysfunctional Attitude Scale]. Diagnostica, 31, 312-323.

Hazen, A. L., Walker, J. R., \& Stein, M. B. (1994). Comparison of Anxiety Sensitivity in Panic Disorder and Social Phobia. Anxiety, 1, 298-301. https:/doi.org/10.1002/anxi.3070010610

In-Albon, T., Suppiger, A., Schlup, B., Wendler, S., Margraf, J., \& Schneider, S. (2008). Validität des Diagnostischen Interviews bei psychischen Störungen (DIPS für DSM-IV-TR) [Validity of the Diagnostisches Interview bei psychischen Störungen (DIPS für DSM-IV-TR)]. Zeitschrift für Klinische Psychologie und Psychotherapie: Forschung und Praxis, 37, 33-42.

Jacobi, F., Höfler, M., Siegert, J., Mack, S., Gerschler, A., Scholl, L., Busch, M. A., Hapke, U., Maske, U., Seiffert, I., Gaebel, W., Maier, W., Wagner, M., Zielasek, J., \& Wittchen, H. U. (2014). Twelve-Month Prevalence, Comorbidity and Correlates of Mental Disorders in Germany: The Mental Health Module of the German Health Interview and Examination Survey for Adults (DEGS1-MH). International Journal of Methods in Psychiatric Research, 23, 304319. https:/doi.org/10.1002/mpr.1439

Kessler, R. C., Petukhova, M., Sampson, N. A., Zaslavsky, A. M., \& Wittchen, H. U. (2012). Twelve-Month and Lifetime Prevalence and Lifetime Morbid Risk of Anxiety and Mood Disorders in the United States. International Journal of Methods in Psychiatric Research, 21, 169- 
184. https:/doi.org/10.1002/mpr.1359

Margraf, J., \& Ehlers, A. (2007). BAI. Beck-Angstinventar. Manual. Deutsche Bearbeitung [BAI: Beck Anxiety Inventory. Manual. German Adaptation]. Frankfurt AM: Harcourt.

Margraf, J., Schneider, S., \& Spörkel, H. (1991). Therapiebezogene Diagnostik: Validität des Diagnostischen Interviews für psychische Störungen (DIPS) [Therapy-Oriented Diagnosis: The Validity of the Diagnostic Interview for Mental Disorders (DIMD)]. Verhaltenstherapie, 1, 110-119. https:/doi.org/10.1159/000257947

Margraf, J., Schneider, S., Soeder, U., Neumer, S., \& Becker, E. S. (1996). F-DIPS: Diagnostisches Interview bei Psychischen Störungen (Forschungsversion). [Diagnostic Interview for Psychological Disorders (Research Version)]. Berlin: Springer.

McWilliams, L. A., Becker, E. S., Margraf, J., Clara, I. P., \& Vriends, N. (2007). Anxiety Disorder Specificity of Anxiety Sensitivity in a Community Sample of Young Women. Personality and Individual Differences, 42, 345-354. https:/doi.org/10.1016/j.paid.2006.07.016

Michael, T., Zetsche, U., \& Margraf, J. (2007). Epidemiology of Anxiety Disorders. Psychiatry, 6, 136-142. https:/doi.org/10.1016/j.mppsy.2007.01.007

Otto, M. W., Teachman, B. A., Cohen, L. S., Soares, C. N., Vitonis, A. F., \& Harlow, B. L. (2007). Dysfunctional Attitudes and Episodes of Major Depression: Predictive Validity and Temporal Stability in Never-Depressed, Depressed, and Recovered Women. Journal of Abnormal Psychology, 116, 475-483. https:/doi.org/10.1037/0021-843X.116.3.475

Peterson, R., \& Reiss, S. (1987). Test Manual for the Anxiety Sensitivity Index. Orland Park, IL: International Diagnostic Systems.

Pigott, T. A. (2003). Anxiety Disorders in Women. Psychiatric Clinics of North America, 26, 621672. https:/doi.org/10.1016/S0193-953X(03)00040-6

Rapee, R. M., \& Heimberg, R. G. (1997). A Cognitive-Behavioral Model of Anxiety in Social Phobia. Behaviour Research and Therapy, 35, 741-756.

https:/doi.org/10.1016/S0005-7967(97)00022-3

Reiss, S., Peterson, R. A., Gursky, D. M., \& McNally, R. J. (1986). Anxiety Sensitivity, Anxiety Frequency and the Predictions of Fearfulness. Behaviour Research and Therapy, 24, 1-8. https:/doi.org/10.1016/0005-7967(86)90143-9

Sapach, M. J. N. T., Carleton, R. N., Mulvogue, M. K., Weeks, J. W., \& Heimberg, R. G. (2015). Cognitive Constructs and Social Anxiety Disorder: Beyond Fearing Negative Evaluation. Cognitive Behaviour Therapy, 44, 63-73. https://doi.org/10.1080/16506073.2014.961539

Schlenker, B. R., \& Leary, M. R. (1982). Social Anxiety and Self-Presentation: A Conceptualization Model. Psychological Bulletin, 92, 641-669. https:/doi.org/10.1037/0033-2909.92.3.641

Schneider, S., Margraf, J., Spörkel, H., \& Franzen, U. (1992). Therapiebezogene Diagnostik: Reliabilität des Diagnostischen Interviews bei psychischen Störungen (DIPS) [Therapy-Related Diagnosis: Reliability of the Diagnostic Interview for Mental Disorders (DIMD)]. Diagnostica, $38,209-227$.

Spence, S. H., \& Rapee, R. M. (2016). The Etiology of Social Anxiety Disorder: An EvidenceBased Model. Behaviour Research and Therapy, 86, 50-67.

https://doi.org/10.1016/j.brat.2016.06.007

Suppiger, A., In-Albon, T., Hendriksen, S., Hermann, E., Margraf, J., \& Schneider, S. (2009). Acceptance of Structured Diagnostic Interviews for Mental Disorders in Clinical Practice and Research Settings. Behavior Therapy, 40, 272-279. https:/doi.org/10.1016/j.beth.2008.07.002

Suppiger, A., In-Albon, T., Herren, C., Bader, K., Schneider, S., \& Margraf, J. (2008). Reliabilität des diagnostischen Interviews bei psychischen Störungen (DIPS für DSM-IV-TR) unter klinischen routinebedingungen [Reliability of the Structured Diagnostic Interview for Mental 
Disorders (DIPS for DSM-IV-TR) in Clinical Routine]. Verhaltenstherapie, 18, 237-244. https:/doi.org/10.1159/000169699

Taylor, S., Koch, W. J., \& McNally, R. J. (1992). How Does Anxiety Sensitivity Vary across the Anxiety Disorders? Journal of Anxiety Disorders, 6, 249-259. https:/doi.org/10.1016/0887-6185(92)90037-8

Trumpf, J., Vriends, N., Meyer, A. H., Becker, E. S., Neumer, S.-P., \& Margraf, J. (2010). The Dresden Predictor Study of Anxiety and Depression: Objectives, Design, and Methods. Social Psychiatry and Psychiatric Epidemiology, 45, 853-864. https:/doi.org/10.1007/s00127-009-0133-2

Vriends, N., Becker, E. S., Meyer, A. H., \& Margraf, J. (2011). Incidence of DSM-IV Social Phobia in a Community Sample of Young German Women. German Journal of Psychiatry, 14, 80-90.

Watson, D., Clark, L. A., \& Carey, G. (1988). Positive and Negative Affectivity and Their Relation to Anxiety and Depressive Disorders. Journal of Abnormal Psychology, 97, 346-353. https:/doi.org/10.1037/0021-843X.97.3.346

Watson, D., Gamez, W., \& Simms, L. J. (2005). Basic Dimensions of Temperament and Their Relation to Anxiety and Depression: A Symptom-Based Perspective. Journal of Research in Personality, 39, 46-66. https:/doi.org/10.1016/j.jrp.2004.09.006

Weich, S., Churchill, R., \& Lewis, G. (2003). Dysfunctional Attitudes and the Common Mental Disorders in Primary Care. Journal of Affective Disorders, 75, 269-278. https:/doi.org/10.1016/S0165-0327(02)00053-8

Weissman, A. N. (1979). The Dysfunctional Attitude Scale: A Validation Study. Publicly Accessible Penn Dissertations, Philadelphia, PA: University of Pennsylvania.

Wittchen, H.-U., Stein, M. B., \& Kessler, R. C. (1999). Social Fears and Social Phobia in a Community Sample of Adolescents and Young Adults: Prevalence, Risk Factors and Co-Morbidity. Psychological Medicine, 29, 309-323. https:/doi.org/10.1017/S0033291798008174

Zuroff, D. C., Igreja, I., \& Mongrain, M. (1990). Dysfunctional Attitudes, Dependency, and Self-Criticism as Predictors of Depressive Mood States: A 12-Month Longitudinal Study. Cognitive Therapy and Research, 14, 315-326. https:/doi.org/10.1007/BF01183999

Submit or recommend next manuscript to SCIRP and we will provide best service for you:

Accepting pre-submission inquiries through Email, Facebook, LinkedIn, Twitter, etc.

A wide selection of journals (inclusive of 9 subjects, more than 200 journals)

Providing 24-hour high-quality service

User-friendly online submission system

Fair and swift peer-review system

Efficient typesetting and proofreading procedure

Display of the result of downloads and visits, as well as the number of cited articles

Maximum dissemination of your research work

Submit your manuscript at: http://papersubmission.scirp.org/

Or contact psych@scirp.org 